Rebello Filho, Wanderley e Bernardo, Christianne. Guia Prático de Direito Ambiental. - Rio de Janeiro: Editora Lumen Juris, 1998.

Sampaio, Francisco José Marques. "O dano ambiental e a responsabilidade". In: Revista Forense. V.317. - Rio de Janeiro: Forense, 1992.
Sampaio, Francisco José Marques. Responsabilidade Civil e Reparação de Danos ao Meio Ambiente. 2ª ed. - Rio de Ja neiro: Editora Lumen Juris, 1998.

Schmidt, Reiner. Einführung in das Umweltrecht. $4^{\mathrm{a}}$ ed. - Munique: C. $\mathrm{H}$. Beck, 1995.

\section{Direitos Fundamentais de Terceira Geração}

Teoxi OAlbino Lavascki

Professor na Faculdade de Direito da UFRGS

\begin{tabular}{|} 
SUMÁRIO \\
I - Introdução. \\
II - Os direitos fundamentais e sua evo- \\
lução. \\
III - Direitos de primeira geração: a li- \\
berdade. \\
IV - Direitos de segunda geração: a \\
igualdade. \\
V - Direitos de terceira geração: a \\
fraternidade. \\
VI - Os juristas do novo tempo. \\
VII - Conclusão: a valorização das qua- \\
lidades humanas do jurista.
\end{tabular}

idades humanas do jurista.

\section{Introdução}

¿lenidades como esta, de colação de grau, constituem uma espécie de cerimônia no convés de um navio que atraca no porto, chegado de uma longa viagem. Presentes, alguns dos marinheiros responsáveis pela navegada, nosso diretor, os professores e funcionários homenageados. Perfilados, os formandos, viajantes sorridentes, semblantes iluminados, olhar feliz, prontos para o desembarque, a jornada chegou ao seu final; no peito, quiçá um aperto estranho, já uma ponta de nostalgia, porque se aqui é um porto de chegada, é igualmente um lugar de despedidas. Ali, no cais, familiares e amigos, ansiosos para o abraço e o aconchego. Mais adiante, a cidade e as suas ruas, e depois as estradas e os seus rumos, a vida e os seus destinos. É da tradição que nessa hora - a um só tempo de chegada e de partida - se ouça a palavra do paraninfo. Sei bem o que isso significa: antes de ser marinheiro também já fui viajante, e, passados vinte e três anos, ainda sinto aqui a presença do Professor Pereira Leite, paraninfo de minha Turma, a quem presto 
saudosa homenagem; ouço ecoar neste sa lão de atos sua voz corajosa, suas palavras candentes na defesa do estado de direito, à época comprometido pela ditadura militar. Por razões que só o afeto explica, sou eu quem traz consigo hoje a imerecida honra de paraninfar a turma de acadêmicos.

\section{Os direitos fundamentais e sua evolução}

Meus queridos afilhados, nesse tempo todo em que estivemos juntos, ouvistes de mim palavras sobre processo civil e seus institutos, sobre petições e litisconsórcios, sobre ônus da prova e medidas cautelares. Juntos procuramos o despertar para o raciocínio da lógica jurídica, seus sistemas de valores e seus princípios. Pois nesta noite, gostaria de falar de um tema sobre o qual não tenho lembrança de termos conversado abertamente, e isso talvez pela singela razão de que não é tema que costume fre qüentar, ao menos com a intensidade que deveria, os programas acadêmicos. Quero falar sobre sentimentos. Sobre coisas do coração.

Muitos hão de imaginar que o assunto escolhido quebra uma das boas tradições da Casa. Muito pelo contrário. $\mathrm{O}$ que desejo justamente demonstrar é que não há a incompatibilidade temática. Sentimento e direito devem andar juntos, de mãos dadas, já que o verdadeiro Estado de Direito, nesses albores do século XXI, não se alcançará sem que se promova uma profunda renovação dos espíritos.

Conta-se que Piero Calamandrei, um dos grandes mestres do direito processual italiano, costumava propor ao estudo de seus alunos um tema de sua especial predileção: o sentimento da sentença ${ }^{1}$. Nessas oportunidades, ensinava que a própria palavra "sentença" provem do verbo "sentir", tal como a palavra sentimento. Não que as sentenças fossem um simples produto dos impulsos subjetivos dos juízes, sem qualquer referencial de natureza jurídica. Claro que não. Porém, dizia ele, em muitas ocasiões, a motivação verdadeira, real e efetiva de uma sentença não está completamente revelada na sua fundamentação técnica. Há nela também razões ocultas, implícitas, inconscientes quase sempre, a influenciar a decisão. É preciso sensibilidade para captá-las. São produto do sentimento do juiz, de suas inclinações, de sua formação, de suas circunstâncias, de seus afetos, de suas tendências, de suas convicções, enfim de todas as variações desta realidade misteriosa, maravilhosa, terrível, que é o espírito humano, refletida, com ou sem véus, nas frias expressões dos repertórios de jurisprudência e nos silenciosos escaninhos dos cartórios.

Esse modo como Calamandrei via o processo final de interpretação e aplicação do direito pelos juízes constitui, na verdade, o estuário de uma corrente evolutiva desenvolvida sobretudo nesses últimos três séculos. Um olhar para a história do direito moderno evidencia, com efeito, que no decorrer do século XVIII começou a brotar e ganhar corpo, no mundo ocidental, a idéia dos chamados "direitos fundamentais", vin-

\footnotetext{
1. A propósito: Mauro Cappelletti, "A ideologia no processo civil", trad. Athos Gusmão Carneiro, Revista de Jurisprudência do
} Tribunal de Justiça do Rio Grande do Sul, vol. 4, p. 1.

Revista da Faculdade de Direito da UFRGS, v. 15, 1998 do eles a alcançar significado universal com a célebre "Declaração dos Direitos do Homem", da Revolução Francesa. O gênio francês conseguiu sintetizar em seu lema revolucionário, os princípios básicos da dignidade humana: liberdade, igualdade, fraternidade. Desde então, o que se tem verificado na história do direito é um processo de gradativa, cumulativa e seqüencial institucionalização dessas aspirações, que aos poucos vão sendo retiradas de sua dimensão puramente filosófica e abstrata e vão sendo inseridas nos ordenamentos jurídicos positivos, de modo a ganhar as indispensáveis condições para a sua concretude material.

\section{Direitos de primeira geração: a liberdade}

Assim, o século XIX foi tomado pela normatização do primeiro desses ideais: os direitos fundamentais de liberdade, por isso denominados "direitos de primeira geração". Naquele século, ganharam densidade normativa os direitos civis e políticos, direitos do indivíduo contra o Estado. Quebrou-se a espinha dorsal do Estado absolutista e de suas cinzas se modelou um Estado liberal, não intervencionista, garantidor das liberdades individuais, com escassa margem de atuação nas relações sociais.

O liberalismo individualista substrato ideológico dos direitos de primeira geração - tinha como princípio político o de que os homens e a sociedade por eles formada têm que realizar diretamente o seu próprio destino. Ao Estado caberia, apenas, deixar as pessoas agirem livremente. Imaginava-se que, rompida a opressão estatal, os direitos de liberdade fariam frutificar uma espécie de harmonia espontânea na convivência sociopolítica.

Todavia, superada a fase de combate ao absolutismo, percebeu-se que era insuficiente, e até mesmo falsa, a idéia de harmonia social espontânea. Como a experiência histórica acabou demonstrando, o liberalismo puro aniquilava o segundo ideal dos revolucionários franceses: o ideal da igualdade. Num estado absenteísta e omisso, a igualdade entre as pessoas era simplesmente formal, desprovida de qualquer representatividade no plano dos fatos, um mero catálogo de ilusões.

\section{Direitos de segunda geração: a igualdade}

E então, a grande crise do Estado liberal em fins do século passado, fez a humanidade dar um passo adiante. Sem renunciar aos direitos de liberdade, conquistados a duras penas, sem voltar atrás no longo caminho percorrido, o novo século já nasceu iluminado pela necessidade de implementar os direitos de igualdade. A doutrina social da Igreja, as filosofias igualitárias e humanistas, a Constituição Mexicana de 1917, a Alemã de 1919, foram marcos importantíssimos na configuração de uma "segunda geração" de direitos fundamentais: os chamados direitos econômicos e sociais. Operou-se, na verdade, um fenômeno de expansão qualitativa dos próprios direitos de liberdade. Já não se buscava, apenas, assegurar a liberdade do indivíduo em face do Estado, mas, mais que isso, procuravam-se os meios aptos para assegurar a liberdade do indivíduo em face 
dos demais indivíduos. Em outras palavras, os direitos sociais e econômicos entraram na história do constitucionalismo pela indeclinável obrigação ética e jurídica de serem estabelecidos padrões mínimos de uma sociedade igualitária.

Modelado à base dessa segunda geração de direitos fundamentais, nasceu o chamado Estado do bem-estar social. E, assim, o século $\mathrm{XX}$ foi todo ele dominado pela força propulsora dos direitos fundamentais inspirados na igualdade. Não há estatuto jurídico, no atual estágio de nosso direito ocidental, que não contenha pautas de reconhecimento explícito de direitos desta natureza igualitária, como por exemplo, o direito à saúde, o direito à habitação, o direito à educação, o direito a padrões salariais indispensáveis à sobrevivência, o direito à seguridade social. Os Estados, outrora omissos, agora proclamam compromis sos solenes de estabelecer políticas públicas destinadas a eliminar desigualdades sociais e de promover, em todos os seus aspectos, a dignidade da pessoa humana.

Porém, neste final de século, também os direitos sociais estão em crise. Há uma profunda crise de efetividade. $O$ modelo estatal imaginado para implementar os direitos de segunda geração, conseguiu vê-los reconhecidos no plano das normas, o que, sem dúvida, representou um notável avanço; mas não teve força ou vontade suficiente para implementá-los, de modo satisfatório, no plano dos fatos. Ruíram os regimes socialistas e as chamadas "democracias ocidentais" se mostram ainda inca-

pazes de transformar em realidade o ideário de suas plataformas humanistas.

\section{Direitos de terceira geração: a fraternidade}

O esgotamento do modelo, todavia, faz com que, mais uma vez, os homens e as mulheres do nosso tempo sejam chamados a dar um novo e importante passo à frente. Têm-se consciência, no moderno constitucionalismo, de que, assim como o ideal de liberdade não pôde ser adequadamente cumprido sem a implementação efetiva e material dos direitos de igualdade - $\mathrm{e}$ daí o surgimento do Estado do bem-estar social - também não se poderá implantar uma sociedade igualitária sem que se promova a efetivação do terceiro sonho dos revolucionários franceses: o sonho da fraternidade.

Nascem, assim, neste limiar de um novo século, os chamados direitos de "terceira geração", inspirados nos valores da solidariedade ${ }^{2}$. O que vemos, hoje, são sinais marcantes de que a humanidade está modelando Estados sem fronteira e fazendo surgir um novo cidadão, um cidadão universal, um cidadão de todas as pátrias. Ganha força e valorização a idéia de que o verdadeiro Estado de Direito - de liberdade e de igualdade entre as pessoas - somente poderá ser construído com reformas não apenas das leis ou das estruturas de poder. A reforma mais urgente, mais profunda, $\mathrm{e}$ certamente a mais difícil, mas que precisará ser feita, é a reforma do próprio ser humano, é a renovação dos espíritos, é a

2. German J. Bidart Campos, Teoria General de los Derechos Humanos, Buenos Aires, Ed. Astrea, 1991, p. 189; Paulo Bonavides, Curso de Direito Constitucional, $4^{3}$ ed., São Paulo, Malheiros, 1993, p. 481. mudança que se opera pela via do coração. O século XXI há de ser marcado, necessariamente, pelo signo da fraternidade ${ }^{3}$. O Estado do futuro não deverá ser apenas um Estado liberal, nem apenas um Estado do social: precisará ser um Estado da solidariedade entre os homens.

\section{Os juristas do novo tempo}

E é esse o ponto onde eu queria chegar, meus queridos afilhados, quando me propus a falar sobre "coisas do coração". $\mathrm{O}$ maior desafio de nosso tempo é quase utópico. É mais do que um desafio, porém. É um dever: o dever de implementar os direitos fundamentais de "terceira geração", os direitos de fraternidade. Está escrito em nossa Carta Política de 1988: constitui objetivo fundamental da República Federativa do Brasil "construir uma sociedade livre, justa e solidária". Esse é o nosso compromisso perante a história.

Portanto, o que esperar do jurista afinado com o novo tempo? Diria que o jurista há de ter, em primeiro lugar, uma visão do seu ofício voltada à eficácia social das normas. E o que isso significa? Significa dirigir a sua energia e a sua inteligência no sentido de reduzir, o quanto possível, a ainda imensa distância que existe entre o mundo normativo e o mundo real. Cumprida toda uma trajetória de avanços sociais no mas garantias de cumprimento dos direitos. Os direitos, na esfera programática, foram plano formal, já não se reclamam direitos, quase todos atendidos pelo constituinte, de modo que não deve ser esse o objeto principal de nossos cuidados. Formalismos à parte, o verdadeiro problema da nossa época consiste em criar mecanismos para garantir a efetividade dos direitos sociais básicos previstos nos textos legislativos. Decididamente, os tempos atuais já não comportam juristas encastelados num mundo de elucubrações teóricas, de costas para a realidade e para a sociedade em que vivem. Não podemos dar razão aos que acham que os juristas, pelas suas tresnoitadas teorias, conceitos e formulações, representam, aos olhos da generalidade dos demais seres humanos, espécimes de uma fauna em vias de extinção, e, por isso mesmo, menos decisiva no curso da vida social, enquanto juristas $^{4}$.

Também não se permite ao jurista autêntico supor que o caminho da efetividade social possa ser alcançado pela juízos subjetivos de mera oportunidade circunstancial, ou pela substituição da axiologia constitucional por ideologias pessoais. Não nos iludamos com os chamados sistemas alternativos de direito. Não podemos supor legítimo o desprezo das normas jurídicas criadas por mecanismos ungidos pelo voto popular, em favor de normas criadas aleatória e arbitrariamente ao sabor das circunstâncias. Tais caminhos representariam a negação da única fonte de legitimidade do direito, que é a Constituição democrática. A busca da eficácia social do substituição dos juízos de legalidade por

Adolio Gelsi Bidart, De Derechos, Deberes y Garantias, del Hombre Comum, Montevideo, Fundacion de Cultura Universitána, 1987, p. 147.

4. Eduardo Novoa Monreal, O Direito como Obstáculo à Transformaçăo Social, trad. Gérson Pereira dos Santos, Porto Alegre, Sérgio A. Fabris Editor, 1988, p. 36. 
direito deve ser empreendida, isto sim, com a exploração dos mecanismos de hermenêutica oferecidos pelo próprio sistema, que não são poucos, são quase inesgotáveis. É preciso descobri-los, com criatividade, com inteligência, com estudo, com sensibilidade.

\section{Conclusão: a valorização das qualidades humanas \\ do jurista}

Porém, há um componente no ofício dos juristas, sejam eles advogados, juízes ou promotores, que não é alcançado apenas com os recursos da racionalidade ou da técnica interpretativa. É que nesse ofício, meus caros afilhados, nós lidamos, invariavelmente, com pessoas e não com artefatos sem alma; pessoas que sentem, que sofrem, que se alegram, que choram. E a criatura humana é fantástica, é mágica, é imprevisível, a vida é rica, a lei nem sempre alcança os seus segredos e os seus mistérios. Imprescindível, por isso, que o cultor do direito, mais que vasculhar, com o auxílio de lupas, todos os possíveis desdobramentos formalísticos das palavras nos textos das leis, tenha sensibilidade para apreender as men- sagens de vida que do seu conjunto invariavelmente resulta. Isso o levará a descobrir, para seu encanto, que o direito, quando visto como sistema, oferece ao intérprete al. ternativas nem sempre perceptíveis ao primeiro olhar. Pois é nessa hora sagrada, em que se impõe ao jurista a tarefa de escolher uma dentre as várias opções que a razão lhe oferece, é nessa hora que o ser humano entra em cena, se levanta, se expõe e se entrega por inteiro, a dar razão ao velho e sábio Professor Calamandrei: nas sentença há razão, mas nas sentenças há também sentimento ${ }^{5}$.

Enfim, meus queridos afilhados, é essa a mensagem que gostaria de deixar marcada na hora em que nos despedimos: o Direito se faz com boas leis e com bons técnicos, certamente. Mas o bom direito se faz, sobretudo, com juristas que tenham sensibilidade para captar o drama humano que os papéis e os processos insistem em encobrir com frieza. O bom direito se faz com juristas de mente esclarecida, coração aberto e alma iluminada. Muito obrigado.

(Discurso de paraninfo da Turma 96/1 da Faculdade de Direito da UFRGS, proferido em 27.07.96) 